\title{
Epidemiology of idiopathic pulmonary fibrosis
}

\section{Brett Ley Harold R Collard}

Department of Medicine, Division of Pulmonary and Critical Care Medicine, University of California San Francisco, San Francisco, California, USA
Correspondence: Brett Ley

Department of Medicine, Division of Pulmonary and Critical Care Medicine, University of California San Francisco, 505 Parnassus Ave, Box 0111 ,

San Francisco, CA 94I43, USA

$\mathrm{Tel}+\mathrm{I} 4154760735$

Fax + I 415502 I32I

Email brett.ley@ucsf.edu
This article was published in the following Dove Press journal:

Clinical Epidemiology

22 November 2013

Number of times this article has been viewed

\begin{abstract}
Idiopathic pulmonary fibrosis is a chronic fibrotic lung disease of unknown cause that occurs in adults and has a poor prognosis. Its epidemiology has been difficult to study because of its rarity and evolution in diagnostic and coding practices. Though uncommon, it is likely underappreciated both in terms of its occurrence (ie, incidence, prevalence) and public health impact (ie, health care costs and resource utilization). Incidence and mortality appear to be on the rise, and prevalence is expected to increase with the aging population. Potential risk factors include occupational and environmental exposures, tobacco smoking, gastroesophageal reflux, and genetic factors. An accurate understanding of its epidemiology is important, especially as novel therapies are emerging.
\end{abstract}

Keywords: idiopathic pulmonary fibrosis, epidemiology, incidence, prevalence, mortality, risk factors

\section{Introduction}

Idiopathic pulmonary fibrosis (IPF) is a specific form of chronic progressive fibrotic lung disease of unknown cause. ${ }^{1,2}$ It occurs primarily in middle-aged to older adults and is characterized by the underlying histopathological pattern of usual interstitial pneumonia. Its pathobiology is complex and is hypothesized to be driven by the loss of alveolar epithelial cell integrity due to aging, genetic and epigenetic factors, and reactivation of developmental signaling pathways. ${ }^{3}$ Progressive fibrosis with loss of normal lung tissue leads to restricted ventilation, impaired gas exchange, respiratory symptoms and exercise limitation, poor quality of life, and ultimately death. Unfortunately, there are no definitive therapies for IPF, with only one drug shown to potentially slow the progression of disease in clinical trials, ${ }^{4}$ and surgical therapy with lung transplantation available to only a small minority of patients.

We are living in a time of great opportunity and promise in the field of IPF. With central advances in our understanding of disease mechanism, the development of novel agents by academia and industry, and the formation of multicenter networks experienced in the conduct of large clinical trials, there is good reason to believe that we are on the verge of developing multiple effective therapies. As the management options for IPF patients improve, an accurate understanding of the epidemiology of IPF will be important so that health care systems and policy-makers are adequately prepared to facilitate care. 


\section{Historical challenges in studying the epidemiology of IPF}

The epidemiology of IPF remains poorly described for many reasons, but changes in definitions of IPF and complex diagnostic algorithms have proven major challenges. Since the early pathological descriptions of interstitial pneumonia by Hamman and Rich in $1944,{ }^{5}$ multiple conditions that we now consider separate disease entities (eg, nonspecific interstitial pneumonia and desquamative interstitial pneumonia) were lumped in with IPF or one of its other names (eg, cryptogenic fibrosing alveolitis). In 1998, Katzenstein and Myers proposed that the term IPF be reserved for those patients with a histopathological pattern of usual interstitial pneumonia and no identifiable cause for their interstitial lung disease (ILD). ${ }^{6}$ This concept was formalized into diagnostic criteria in the first international consensus statement on IPF in $2000^{1}$ and revised in 2011 (Table 1). ${ }^{2}$ Additionally, these statements have emphasized the importance of a multidisciplinary approach to accurate diagnosis through consensus that includes discussion among pulmonologists, radiologists, and pathologists with expertise in ILDs. This evolution is reflected in the confusing nomenclature of International Classification of Disease (ICD) codes that have historically encompassed the disease (Table 1).

\section{Prevalence and incidence}

The published literature suggests that IPF is the first or second most commonly encountered ILD in pulmonology practices (range 17\%-86\%). ${ }^{7-11}$ Its overall incidence and prevalence, however, are unclear (Table 2). Geographically, most studies come from the United States ${ }^{12-14}$ and Europe (United Kingdom, ${ }^{15,16}$ Czech Republic, ${ }^{17}$ Norway, ${ }^{18}$ Finland, ${ }^{19}$ Greece, ${ }^{8}$ and Turkey ${ }^{9}$ ), with only two studies reported from Asia $\left(\operatorname{Japan}^{11}\right.$ and Taiwan $\left.{ }^{20}\right)$. Most of these studies included

Table I Diagnostic criteria for idiopathic pulmonary fibrosis and International Classification of Disease (ICD) code nomenclature

\begin{tabular}{|c|c|}
\hline Statement/ICD code & Definition/criteria \\
\hline ATS/ERS 2000' & $\begin{array}{l}\text { Surgical lung biopsy showing UIP and } \\
\text { I. Exclusion of secondary causes (ie, drugs, environmental exposures, collagen vascular diseases) } \\
\text { 2. Abnormal PFTs showing restriction and/or impaired gas exchange } \\
\text { 3. Consistent abnormalities on chest X-ray or HRCT } \\
\text { or } \\
\text { Without a surgical lung biopsy must meet } \\
\text { All major criteria } \\
\text { Exclusion of secondary causes, abnormal PFTs, bibasilar reticular abnormalities with minimal ground glass } \\
\text { opacities on HRCT, TBB, or BAL without features of an alternative diagnosis } \\
\text { plus } \\
3 \text { of } 4 \text { minor criteria } \\
\text { Age }>50 \text { years, insidious onset of otherwise unexplained dyspnea on exertion, duration of illness of at } \\
\text { least } 3 \text { months, bibasilar inspiratory crackles }\end{array}$ \\
\hline ATS/ERS/JRS/ALAT 20I I ${ }^{2}$ & $\begin{array}{l}\text { I. Exclusion of secondary causes } \\
\text { 2. UIP pattern on HRCT in patients without a surgical lung biopsy or specific combinations of HRCT and } \\
\text { surgical lung biopsy patterns: }\end{array}$ \\
\hline
\end{tabular}

\begin{tabular}{|c|c|c|c|c|c|c|}
\hline & \multicolumn{6}{|c|}{ Surgical lung biopsy pattern } \\
\hline & HRCT pattern & UIP & Probable UIP & Possible UIP & $\begin{array}{l}\text { Non-classifiable } \\
\text { fibrosis }\end{array}$ & Not UIP \\
\hline & UIP & IPF & IPF & IPF & IPF & Not IPF \\
\hline & Possible UIP & IPF & IPF & MDD & MDD & Not IPF \\
\hline & $\begin{array}{l}\text { Inconsistent } \\
\text { with UIP }\end{array}$ & MDD & Not IPF & Not IPF & Not IPF & Not IPF \\
\hline \multicolumn{7}{|l|}{ ICD-8 } \\
\hline 517 & \multicolumn{6}{|c|}{ Other chronic interstitial pneumonia } \\
\hline \multicolumn{7}{|l|}{ ICD-9 } \\
\hline 515 & \multicolumn{6}{|c|}{ Postinflammatory pulmonary fibrosis } \\
\hline 516.3 & \multicolumn{6}{|c|}{ Idiopathic fibrosing alveolitis } \\
\hline \multicolumn{7}{|l|}{ ICD-I0 } \\
\hline J84.I & \multicolumn{6}{|c|}{ Idiopathic pulmonary fibrosis } \\
\hline
\end{tabular}

Abbreviations: ALAT, Latin American Thoracic Association; ATS, American Thoracic Society; BAL, bronchoalveolar lavage; ERS, European Respiratory Society; HRCT, high-resolution computed tomography; ICD, International Classification of Disease; IPF, idiopathic pulmonary fibrosis; JRS, Japanese Respiratory Society; MDD, further multidisciplinary discussion required; PFTs, pulmonary function tests; TBB, transbronchial biopsy; UIP, usual interstitial pneumonia. 
Table 2 Prevalence and incidence of idiopathic pulmonary fibrosis by geography

\begin{tabular}{|c|c|c|c|c|}
\hline Geography & Study year(s) & $\begin{array}{l}\text { Prevalence } \\
\text { (per } 100,000)\end{array}$ & $\begin{array}{l}\text { Incidence } \\
\text { (per } 100,000 / y)\end{array}$ & Case ascertainment \\
\hline \multicolumn{5}{|l|}{ United States } \\
\hline $\begin{array}{l}\text { New Mexico'2 } \\
\text { (Bernalillo County) }\end{array}$ & $1988-1990$ & $13.2-20.2^{\mathrm{a}}$ & $7.4-10.7^{\mathrm{a}}$ & $\begin{array}{l}\text { Population-based, multiple sources } \\
\text { ICD-9 } 516.3\end{array}$ \\
\hline Twenty states ${ }^{13}$ & 2000 & $14.0-42.7^{b}$ & $6.8-16.3^{b}$ & $\begin{array}{l}\text { Private insurance claims database } \\
\text { ICD-9 } 516.3\end{array}$ \\
\hline $\begin{array}{l}\text { Minnesota }^{14} \\
\text { (Olmsted County) }\end{array}$ & $1997-2005$ & $27.9-63.0^{\mathrm{b}}$ & $8.8-17.4^{b}$ & $\begin{array}{l}\text { Population-based } \\
\text { medical record linkage system } \\
\text { (2000 ATS/ERS criteria) }\end{array}$ \\
\hline \multicolumn{5}{|l|}{ Europe } \\
\hline Czech Republic ${ }^{17}$ & $|98|-1990$ & $6.5-12.1^{c}$ & $0.74-1.28^{c}$ & Clinical registry \\
\hline Norway ${ }^{18}$ & $1984-1998$ & 23.4 & 4.3 & $\begin{array}{l}\text { Hospital district records } \\
\text { ICD-8 and } 9 \text { codes and record review }\end{array}$ \\
\hline Finland ${ }^{19}$ & $1997-1998$ & $16-18$ & - & $\begin{array}{l}\text { Pulmonary clinics and hospital database } \\
\text { ICD-I0 J84.I, subset reviewed } \\
\text { (2000 ATS/ERS criteria) }\end{array}$ \\
\hline Greece $^{8}$ & 2004 & 3.4 & 0.9 & $\begin{array}{l}\text { Survey of pulmonary practices } \\
\text { ( } 2000 \text { ATS/ERS criteria) }\end{array}$ \\
\hline$U^{15}$ & $199 \mid-2003$ & - & 4.6 & Nation-wide primary care database \\
\hline $\mathrm{UK}^{16}$ & $2000-2009$ & - & 7.4 & Nation-wide primary care database \\
\hline Turkey ${ }^{9}$ & $2007-2009$ & - & $4.9^{\mathrm{d}}$ & $\begin{array}{l}\text { Survey of pulmonary practices } \\
\text { ( } 2000 \text { ATS/ERS criteria) }\end{array}$ \\
\hline \multicolumn{5}{|r|}{ 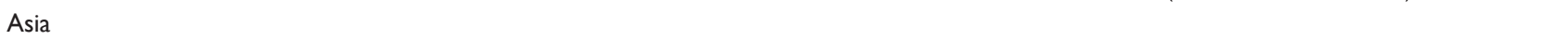 } \\
\hline Taiwan $^{20}$ & 1997-2007 & $0.7-6.4^{e}$ & $0.6-1.4^{\mathrm{e}}$ & $\begin{array}{l}\text { National health insurance database } \\
\text { ICD-9 } 516.3\end{array}$ \\
\hline Japan" & 2005 & $2.9^{f}$ & - & $\begin{array}{l}\text { Medical benefits records and subset } \\
\text { medical record review for IIPs }\end{array}$ \\
\hline
\end{tabular}

Notes: aRange reported for women and men, respectively; ${ }^{b}$ range reported for narrow and broad case definitions; ' range reported for rates over the study period; ${ }^{d}$ incident cases for ILD reported as 25.8 per 100,000/y, where $19.9 \%$ were IPF; erange reported for the broad definition over the study period; f prevalence reported for all IIPs as 3.4 per 100,000 , of which $85.7 \%$ were reported to be IPF.

Abbreviations: ATS, American Thoracic Society; ERS, European Respiratory Society; ICD-8, -9, - I0, International Classification of Disease-eighth, ninth, or tenth revisions; IIP, idiopathic interstitial pneumonia; $y$, year; ILD, interstitial lung disease; IPF, idiopathic pulmonary fibrosis.

patients diagnosed prior to the redefinition of IPF in 2000, and strategies for case ascertainment within the source population varied from exclusive reliance on diagnostic codes (low diagnostic specificity), to surveys of clinicians at subspecialty clinics (low diagnostic sensitivity), to a combination of searching administrative data and focused review of medical records (potentially improving diagnostic sensitivity and specificity). With these issues in mind, the published prevalence of IPF has ranged from 0.7 per 100,000 in Taiwan to 63.0 per 100,000 in the United States, and the published incidence has ranged from 0.6 per 100,000 person years to 17.4 per 100,000 person years (Table 2). It is unclear how much of this variation among studies is due to geographic or demographic differences in the risk of IPF. Below is a brief overview of selected studies.

\section{United States}

\section{Coultas et al ${ }^{12}$}

This study used multiple sources including clinician surveys, pathology reports, discharge diagnoses, death certificates, and autopsies from Bernalillo County, New Mexico between 1988 and 1990. Using the diagnostic code for idiopathic fibrosing alveolitis (ICD-9 code 516.3), an overall prevalence of IPF of 13.2 per 100,000 for women and 20.2 per 100,000 for men (incidence 7.4 per 100,000 person years and 10.7 per 100,000 person years for men and women, respectively) were reported.

\section{Raghu et al $^{13}$}

This study queried a large private health insurance claims database that included patients from 20 states in the United States for calendar year 2000. Cases were again identified by ICD-9 code 516.3 and exclusion of associated conditions (broad definition), with a subgroup analysis requiring additional claims for lung biopsy or chest computed tomography scan, indicating a relevant diagnostic evaluation had taken place (narrow definition). The prevalence was 42.7 per 100,000 (14 per 100,000 for the narrow definition) and the incidence was 16.3 per 100,000 person years ( 6.8 per 100,000 person years for the narrow definition). This translated to an estimated 
89,000 patients living with IPF in the United States in the year 2000 with 34,000 new cases diagnosed per year.

Both the Coultas and Raghu studies also provided estimates using the more generic diagnostic code for postinflammatory pulmonary fibrosis (ICD-9 code 515). Figure 1 demonstrates the impact of this more inclusive (ie, more sensitive, less specific) definition. The wide variation in the prevalence of ICD-9 code 515 between studies may reflect methodological and/or coding practice differences.

\section{Fernández-Pérez et al ${ }^{14}$}

This was a small population-based study in Olmsted County, Minnesota from 1997-2005 (source population of approximately 128,000 primarily White, residents) utilizing a county-wide medical record linkage system. Cases were first identified by administrative codes and then verified via audit of patient-level data in accordance with the revised IPF definition. Investigators identified a total of 47 cases meeting the primary case definition corresponding to an age and sex-adjusted prevalence of 63 per 100,000 and an incidence of 17.4 per 100,000 person years. Incidence rates decreased over the study period.

\section{Europe}

\section{Gribbin et al ${ }^{15}$}

This study interrogated a longitudinal primary care database representing $25 \%$ of practices within the United Kingdom for the diagnostic terms cryptogenic or idiopathic fibrosing

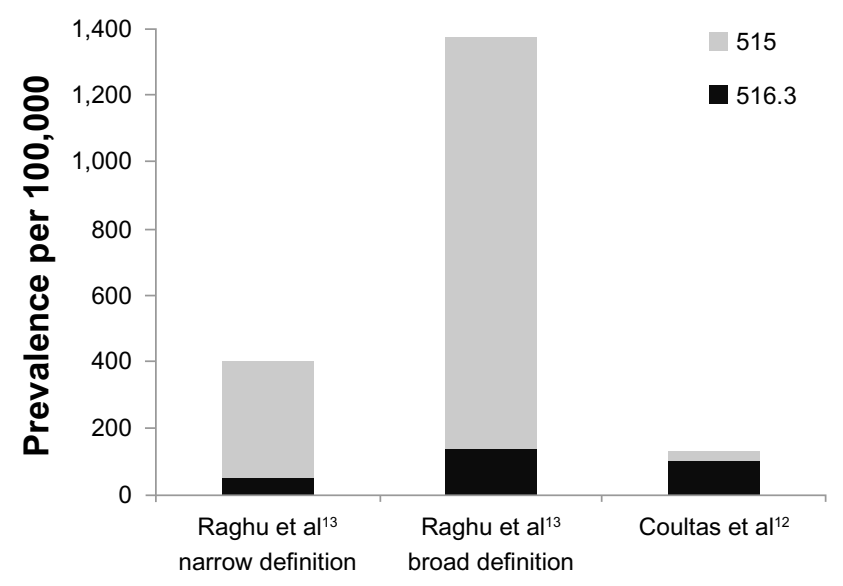

Figure I The prevalence of idiopathic pulmonary fibrosis varies widely depending on case definitions in epidemiologic studies.

Notes: There is marked variation with the use of ICD-9 code 515 (postinflammatory pulmonary fibrosis) and/or ICD-9 code 516.3 (idiopathic fibrosing alveolitis) to identify cases, with or without added levels of stringency. The Raghu et al broad definition required the presence of ICD-9 code 516.3 or 515 and exclusion of other diagnoses that cause interstitial lung disease. The Raghu et al narrow definition required the broad definition plus additional procedure codes for lung biopsy and radiology studies. The Coultas et al cases were drawn from multiple administrative and clinical sources. Estimates are shown for men in the 65-74 year age group from Raghu et al ${ }^{13}$ and Coultas et al ${ }^{12}$. alveolitis between 1991 and 2003. An audit of IPF cases in this database found that 19 of 20 were accurate, supporting diagnostic validity, although the audit occurred prior to the revised criteria. ${ }^{21}$ The overall annual incidence of IPF was 4.6 per 100,000 person years. ${ }^{15}$ Incidence increased over the study period, about $11 \%$ per year. The investigators reported a follow up study with similar methods, albeit with slightly more inclusive search terms, for patients identified from 2000-2009, and found that incidence continued to increase. ${ }^{16}$ The increasing incidence was not accounted for by the effect of an aging population.

\section{von Plessen et $\mathrm{al}^{18}$}

This study searched multiple ICD-8 and ICD-9 codes in one hospital district in Norway between 1984 and 1998. Medical records were reviewed and cases excluded if alternative diagnoses appeared more likely. Prevalence was found to be 23.4 per 100,000 , and the incidence was 4.3 per 100,000 person years.

\section{Hodgson et al ${ }^{19}$}

These researchers performed a nation-wide survey of pulmonary practices in Finland and searched hospital databases for ICD-10 code J84.1 in 1997-1998. A case audit was performed at a subset of centers finding that $49 \%-77 \%$ met revised diagnostic criteria. Prevalence was found to be 16 to 18 per 100,000 .

\section{Karakatsani et al ${ }^{8}$}

In Greece, this study surveyed pulmonary specialty clinics in 2004 for cases of ILD (an approach likely to underestimate disease occurrence compared to population-based approaches), with clinicians instructed to apply consensus criteria. The reported prevalence $(3.4$ per 100,000$)$ and incidence $(0.9$ per 100,000 person years $)$ of IPF were much lower than other reports from the United States and Europe.

\section{Musellim et $\mathrm{al}^{9}$}

Similar methodology to Karakatsani et $\mathrm{al}^{8}$ was used for another study in Turkey, performed from 2007 to 2009. The reported incidence of IPF was 4.9 per 100,000 person years.

\section{Asia}

\section{Ohno et al"}

These investigators searched medical benefit certificates for all idiopathic interstitial pneumonias in Japan in 2005, with clinical data available for review in $35 \%$ of cases. The incidence of idiopathic interstitial pneumonia was 3.4 per 100,000 person years, and $85.7 \%$ were considered due to IPF. 


\section{Lai et $\mathrm{al}^{20}$}

This study searched the Taiwanese national health insurance system for ICD-9 code 516.3 from 1997 to 2007 and applied narrow and broad case definitions similar to the Raghu et $\mathrm{al}^{13}$ study. The prevalence was 0.7 to 6.4 per 100,000 , and the incidence was 0.6 to 1.4 per 100,000 person years.

In both the Ohno and Lai studies, disease severity was high, suggesting that the lower estimates were due to low case ascertainment rates, with only more severe cases recognized.

Many of the above studies evaluated rates of IPF by age and sex. Prevalence and incidence of IPF are clearly higher in older age groups (Figure 2), a finding consistent with the role of aging in the pathogenesis of IPF. ${ }^{3}$ IPF also appears to be more common in men compared to women, however, some postulate this may be due to sex differences in historical smoking patterns rather than an inherent sex-related risk for IPF. 22,23

\section{Risk factors}

Several potential risk factors for the development of IPF have been identified. These include environmental and occupational exposures, tobacco smoking, comorbidities (in particular gastroesophageal reflux disease [GERD]), and genetic polymorphisms (Table 3). The identification of risk factors for IPF is critically important as it may inform prevention strategies, early diagnosis, and novel therapies.

\section{Inhaled exposures}

Multiple lines of evidence lend support to the plausibility of inhaled exposures contributing to at least some cases of IPF. $^{24}$ First, basic science and animal studies support the concept of repetitive alveolar epithelial cell stress due to an array of potential inciting agents in the pathogenesis of IPF. ${ }^{3,24}$ Second, epidemiologic studies have observed geographic variation within countries in the occurrence of IPF, particularly in highly industrialized regions..$^{25}$ There is also a higher occurrence in men compared to women who, at least historically, were more likely to smoke and to work in dusty occupations. ${ }^{12,23,26}$ Third, well-defined occupational lung diseases such as asbestosis and silicosis clearly cause fibrotic lung disease, ${ }^{27,28}$ leaving open the possibility that less wellcharacterized exposures may do so as well. Fourth, autopsy studies have revealed higher levels of inorganic particles, such as silicon and aluminum, in the hilar lymph nodes of patients with IPF compared to controls. ${ }^{29}$

With these observations in mind, several studies have demonstrated an association of certain environmental and occupational exposures with IPF. ${ }^{24}$ As with incidence and prevalence estimation studies, diagnostic misclassification (particularly for studies performed prior to the IPF statements) introduces the potential for faulty associations.

In 2006, Taskar and Coultas reviewed six case-control studies, performed in three countries (United States, United Kingdom, Japan), that compared a total of 711 patients with IPF to 1,491 controls. ${ }^{24}$ Exposures with

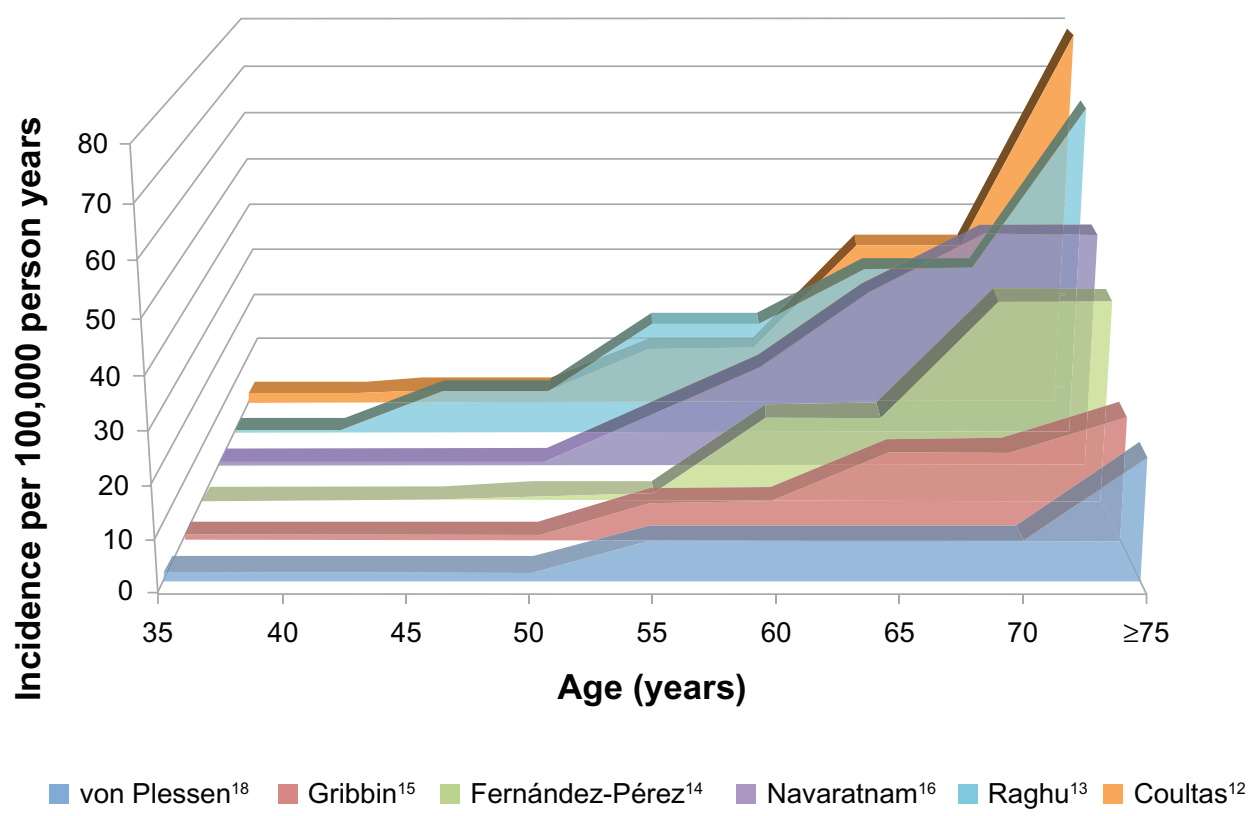

Figure $\mathbf{2}$ The incidence of idiopathic pulmonary fibrosis increases with age.

Notes: For demonstration purposes, some estimates were averaged where reported by sex separately ${ }^{12-14,18}$ (as opposed to combined ${ }^{15,16}$ ). 
Table 3 Proposed risk factors for idiopathic pulmonary fibrosis

\begin{tabular}{l} 
Environmental/occupational \\
Agriculture/farming \\
Birds \\
Hairdressing \\
Livestock \\
Animal/vegetable dust \\
Textile dust \\
Mold \\
Metal dusts \\
Wood dusts \\
Stone/sand/silica \\
Wood fires \\
Tobacco smoke \\
Genetic mutations \\
TERT, TERC (telomerase genes) \\
SPC (surfactant protein C) \\
SPA2 (surfactant protein A2) \\
MUC5B (mucin 5B) \\
ELMOD2 (ELMO domain-containing 2) \\
TOLLIP (toll interacting protein) \\
Comorbidity \\
Gastroesophageal reflux disease \\
Diabetes mellitus \\
Infection \\
Human herpes viruses \\
Hepatitis C virus \\
\hline
\end{tabular}

significant associations in at least one study included agriculture/farming, hairdressing, birds, animal/vegetable dust, livestock, wood dust, textile dust, mold, metal dust, stone/ sand/silica, wood fires, and tobacco smoking. ${ }^{30-35}$ Metaanalysis of exposures with at least two studies demonstrated a significant association for agriculture/farming (odds ratio [OR] 1.65, 95\% confidence interval [CI] 1.20-2.26, and population attributable risk [PAR] 20.8\%), livestock (OR 2.17, 95\% CI 1.28-3.68, PAR 4.1\%), wood dust (OR 1.94, 95\% CI 1.34-2.81, PAR 5.0\%), metal dust (OR 2.44, 95\% CI 1.74-3.40, PAR 3.4\%), stone/sand/silica (OR 1.97, 95\% CI 1.09-3.55, PAR 3.5\%), and smoking (OR 1.58, 95\% CI 1.27-1.97, PAR 49.1\%). ${ }^{24} \mathrm{~A}$ dose-response has been suggested for metal dust exposure ${ }^{34}$ and moderate smoking history. ${ }^{35,36}$ Smoking has also been associated with a higher risk of developing familial pulmonary fibrosis with an age and sex-adjusted odds ratio of 3.6 (95\% CI 1.2-9.8). ${ }^{37}$

Hubbard et al examined death certificates from pension fund archives at a major metal engineering company from 1967-1997, finding a mortality rate from IPF among workers higher than that expected in the general population (proportional mortality ratio $1.39,95 \%$ CI $1.07-1.82){ }^{38}$ They further examined the lifetime occupational records for a subgroup of cases and controls, and found a significant association of IPF with the duration of working with metal
(OR per 10 years 1.71, 95\% CI 1.09-2.68). In 1994 in Japan, Iwai et al examined occupational data on autopsy records from 1,311 patients with IPF compared to 393,000 controls and found a significant association with metal workers, wood workers, painters, and barbers/beauticians. ${ }^{31}$

Four more recent case-control studies have been published from Sweden, the United States, Mexico, and Egypt. In Sweden, Gustafson et al found no relationship with metal dust exposure or the general category of wood dust exposure, though they did find significant associations for men with birch and hardwood dust exposure. ${ }^{39}$ In the United States, Pinheiro et al used national death certificate data from 1999-2003 comparing ICD-10 code J84.1 with matched controls, finding an increased proportionate mortality for metal mining $(2.34,95 \%$ CI 1.3-4.0) and fabricated structural metal products $\left(1.9,95 \%\right.$ CI 1.1-3.1). ${ }^{40}$ In Mexico, GarcíaSancho et al found a significant association for occupational exposure to dusts, smoke, gases, or chemicals. ${ }^{41}$ Finally, in Egypt, Awadalla et al performed a multicenter hospitalbased case control study from 2010 to $2011 .{ }^{42}$ Significant associations were found for occupations in woodworking and chemical/petrochemical industry for men and raising birds and farming for women.

\section{Gastroesophageal reflux}

There is strong evidence linking GERD to the presence and progression of IPF, but causation is unproven. GERD is hypothesized to lead to chronic microaspiration of gastric contents, both acid and nonacid, causing repetitive lung injury and resulting pulmonary fibrosis in susceptible individuals. ${ }^{43}$ This concept is supported by animal studies, ${ }^{43}$ an elevated prevalence of GERD in patients with IPF (67\%-94\%), ${ }^{44-47}$ and an association in retrospective studies of GERD treatment with improved survival and reduced disease progression in IPF. ${ }^{48,49}$ Interestingly, less than half of IPF patients with abnormal gastroesophageal reflux report classic symptoms (eg, heartburn, regurgitation) making it difficult to identify these patients clinically. ${ }^{44-47}$

\section{Genetics}

Familial IPF is defined as IPF occurring in two or more first-degree relatives within the same biologic family. ${ }^{2,50}$ Familial IPF is thought to represent $<5 \%$ of cases of IPF and is generally indistinguishable from sporadic cases. ${ }^{51}$ Genes associated with familial IPF include telomerase-related genes (TERT and TERC), ${ }^{52,53}$ surfactant proteins $\mathrm{C}(S P C)^{54-56}$ and A2 $(S P A 2)^{57}$, and ELMOD2. ${ }^{58}$ Mutations in TERT or TERC have been identified in about $18 \%$ of familial IPF and less 
commonly in sporadic cases. ${ }^{52,53,59}$ These mutations result in shortened telomere lengths in both affected individuals and asymptomatic carriers, and shortened telomere lengths have also been demonstrated in noncarrier family members, suggesting an epigenetic inheritance of short telomeres. ${ }^{52,53}$ Also, $25 \%$ of sporadic and $37 \%$ of familial cases without TERT/TERC mutations have short telomeres, suggesting other mechanisms for telomere shortening that are not due to mutations in TERT/TERC. ${ }^{60}$ Finally, the pulmonary fibrosis in TERT mutation families is age-dependent, associated with smoking, and confers a survival prognosis similar to sporadic IPF ${ }^{61}$ The telomere story in IPF provides important potential pathogenic links with epidemiologic observations of increased risk of IPF with aging and smoking.

A common single nucleotide polymorphism in the promoter region of the mucin $5 \mathrm{~B}$ gene (MUC5B) was discovered in $38 \%$ of sporadic IPF cases and $9 \%$ of controls. ${ }^{62}$ The association was found to be allele dose-dependent and has been replicated in independent cohorts. ${ }^{62,63}$ Interestingly, while the $M U C 5 B$ promoter polymorphism appears to confer increased risk of developing IPF, it may be associated with improved survival in established IPF. ${ }^{64}$ Finally, two large genome-wide association studies have recently confirmed associations with TERT, TERC, and MUC5B as well as other novel loci (eg, TOLLIP), some of which are thought to be involved in host defense, cell-cell adhesion, and DNA repair. ${ }^{65,66}$

\section{Heath care resource utilization and burden of illness}

Until recently, little was known about health care resource utilization and burden of illness related to IPF. Most of the literature has focused on hospitalizations which are costly and associated with a poor prognosis similar to other chronic respiratory diseases. ${ }^{67}$ In IPF, hospital admissions are often due to respiratory worsening and are associated with reduced survival. ${ }^{68-70}$ At least half of hospitalizations are thought to be due to acute exacerbations of IPF, defined as respiratory worsening over less than 1 month without an identifiable secondary cause, such as infection. ${ }^{69,71}$ Based mostly on retrospective studies, the annual incidence of acute exacerbations of IPF ranges from approximately $5 \%-20 \%$, with a mortality rate of $20 \%-100 \%{ }^{69,71}$ In their population-based study, FernándezPérez et al found that $79 \%$ of IPF patients in Olmsted county, Minnesota required one or more hospitalizations for acute respiratory worsening at a rate of 0.13 hospitalizations per patient year. ${ }^{14}$ In the UK, Navaratnam et al explored hospitalization for IPF from 1998 to $2010 .{ }^{72}$ The admission rate for ICD-10 code J84. 1 averaged 14.95 per 100,000 person years and increased by approximately $5 \%$ per year. Admission rates were greater in older patients and in men. The average length of stay decreased from 7.2 days to 5.1 days, but the estimated financial burden of hospitalization increased from $£ 12$ million to $£ 16.2$ million per year.

Collard et al assessed the overall burden of illness in IPF including comorbidities, health care resource utilization, and health care costs by searching two United States insurance claims databases between 2001 and $2008 .{ }^{73}$ Cases of IPF required both age $>55$ years old and at least two claims of ICD-9 code 516.3 or one claim each with ICD-9 code 516.3 and 515. An age and sex-matched population lacking these codes was used for control comparisons. Pulmonary hypertension, emphysema, pulmonary embolism, chronic bronchitis, pulmonary infection, and lung cancer were all more common in IPF patients than controls. Risk was also increased for many common chronic diseases, such as coronary artery disease, diabetes, congestive heart failure, and GERD. The all-cause hospitalization rate $(0.5$ per person year), the days in hospital (3.1 days per person year), and the outpatient visit rate (28 visits per person year) were two-fold higher than for controls, and the inpatient death rate was more than three-fold higher than for controls. The average annual direct costs were about two-fold higher for IPF patients compared to controls, amounting to an incremental annual cost of $\$ 12,124$. Based on a prevalence of 89,000 patients with IPF in the United States, ${ }^{13}$ it was estimated that the aggregate incremental cost due to IPF was over $\$ 1$ billion per year.

\section{Mortality}

IPF-related mortality refers to the proportion of people dying per year in the general population in whom IPF is considered the underlying cause of death or an associated cause of death. IPF-related mortality data are typically obtained from national registries compiled from information on death certificates. These studies are generally limited by disease under-recognition (patients with IPF are not captured) and diagnostic misclassification (patients with IPF are mislabeled). Coultas and Hughes evaluated death certificates for 129 patients with a known clinical diagnosis of ILD. ${ }^{7}$ Looking at potential IPF cases (ICD-9 code 515 and 516.3 combined), 36 of 71 patients with the diagnosis prior to death had it listed anywhere on the death certificate (diagnostic sensitivity $51 \%$ ). There was a high degree of reclassification between ICD-9 codes 515 and 516.3 comparing predeath and death certificate diagnoses. Johnston et al reported similar findings. ${ }^{26}$ These data taken together suggest that mortality 
data from national death registries underestimate IPF-related mortality.

Three studies examined mortality from IPF in the 1970s to early 1990s in the United Kingdom, United States, Germany, Australia, New Zealand, and Canada. 22,26,74 Major findings were that IPF-related mortality 1 ) increased in most countries over this time period, 2) was higher in older patients and in men, and 3) had regional variations within countries. These studies also highlighted a marked difference in rates of ICD-9 code 516.3 versus 515 among the countries, reflecting differences in country-specific coding practices.

Olson et al investigated mortality rates in IPF by searching the United States death registry from 1992 to $2003 .{ }^{23}$ IPF was identified as records containing ICD-9 code 516.3 or 515 (from 1992-1998) and ICD-10 code J84.1 (from 1998-2003) excluding those containing codes for other ILDs. The average age and sex-adjusted mortality was 5.08 per 100,000 person years, which is similar to contemporary incidence estimates in the United States (6.8 per 100,000 patients years ${ }^{2}$ to 8.8 per 100,000 patient years). ${ }^{14}$ Mortality was higher than previously reported ${ }^{22}$ and increased by $34 \%$ over the study period. Although mortality rates were higher for men compared to women, they increased more rapidly in women, potentially due to changes in smoking patterns. Mortality rates were higher in older age groups and in Whites compared to Blacks and Hispanics. IPF was the most common underlying cause of death in patients with IPF $(60 \%)$, with other common causes including ischemic heart disease, lung cancer, pneumonia, cerebrovascular disease, heart failure, and pulmonary embolism. Interestingly, the proportion of patients dying from IPF, rather than with IPF, was greater in this study than in previous reports. ${ }^{22}$ The authors speculate this may be due to effective therapies for competing causes of death, such as cardiovascular disease, outpacing those for IPF.

In a follow up study using similar methods during the years 1989 to 2007, these investigators further explored racial and ethnic differences in IPF mortality. ${ }^{75}$ Of all IPF-related deaths, $87.2 \%$ occurred in Whites, $5.1 \%$ in Blacks, $5.4 \%$ in Hispanics, and $2.2 \%$ in other racial/ethnic groups. Compared to Whites, Blacks were less likely (OR 0.47) and Hispanics (OR 1.45) and other groups (1.29) more likely to have IPF encoded on their death certificates after adjusting for age and sex.

Navaratnam et al searched national mortality statistics in the United Kingdom for underlying cause of death from 1968 to 2008 using ICD-8, ICD-9, and ICD-10 codes spanning this period. ${ }^{16}$ Mortality, standardized to the 2008 population, increased from 0.92 per 100,000 person years in 1968-1972 to 5.1 per 100,000 person years in 2005-2008; an annual increase of 5\% after controlling for age and sex. Again, mortality rates were higher in men and older age groups.

Whether the increasing mortality from IPF is due to a true increase in mortality or is a consequence of recognition or reporting bias is uncertain. In public health terms, IPFrelated mortality is similar in magnitude to that of many malignancies (eg, non-Hodgkin's lymphoma, renal cancer, esophageal cancer). ${ }^{76}$

\section{Conclusion}

Idiopathic pulmonary fibrosis is an uncommon disease, but its incidence and prevalence appear to be increasing, and may be higher than reported in the literature because of reporting and recognition bias. There is still a lot we have to learn about the epidemiology of the disease; at present, there are entire continents without any available data on the occurrence of IPF. The risk of developing IPF is likely due to both host and environmental factors, and their elucidation may lead to improved prevention and treatment strategies. The personal and financial costs of IPF are substantial, and therapies to reduce the burden of illness from IPF are sorely needed.

\section{Disclosure}

$\mathrm{HRC}$ has served as consultant for Biogen, FibroGen, Genoa, Gilead, InterMune, MedImmune, Promedior, and Pfizer; has received grants from Boehringer-Ingelheim, Genentech, and the National Institutes of Health National Heart, Lung, and Blood Institute; has received royalties from UpToDate; and has received payment for development of educational presentations from MedScape. BL reports no conflicts of interest in this work.

\section{References}

1. American Thoracic Society. Idiopathic pulmonary fibrosis: diagnosis and treatment. International consensus statement. American Thoracic Society (ATS), and the European Respiratory Society (ERS). Am J Respir Crit Care Med. 2000;161(2 Pt 1):646-664.

2. Raghu G, Collard HR, Egan JJ, et al; ATS/ERS/JRS/ALAT Committee on Idiopathic Pulmonary Fibrosis. An official ATS/ERS/JRS/ALAT statement: idiopathic pulmonary fibrosis: evidence-based guidelines for diagnosis and management. Am J Respir Crit Care Med. 2011;183(6): 788-824.

3. King TE Jr, Pardo A, Selman M. Idiopathic pulmonary fibrosis. Lancet. 2011;378(9807):1949-1961.

4. Noble PW, Albera C, Bradford WZ, et al; CAPACITY Study Group. Pirfenidone in patients with idiopathic pulmonary fibrosis (CAPACITY): two randomised trials. Lancet. 2011;377(9779):1760-1769.

5. Hamman L, Rich AR. Acute diffuse interstitial fibrosis of the lungs. Bull Johns Hopkins Hospital. 1944;74:177-212.

6. Katzenstein AL, Myers JL. Idiopathic pulmonary fibrosis: clinical relevance of pathologic classification. Am J Respir Crit Care Med. 1998;157(4 Pt 1):1301-1315. 
7. Coultas DB, Hughes MP. Accuracy of mortality data for interstitial lung diseases in New Mexico, USA. Thorax. 1996;51(7):717-720.

8. Karakatsani A, Papakosta D, Rapti A, et al; Hellenic Interstitial Lung Diseases Group. Epidemiology of interstitial lung diseases in Greece. Respir Med. 2009;103(8):1122-1129.

9. Musellim B, Okumus G, Uzaslan E, et al. Turkish Interstitial Lung Diseases Group. Epidemiology and distribution of interstitial lung diseases in Turkey. Clin Respir J. Epub May 27, 2013.

10. Thomeer MJ, Costabe U, Rizzato G, Poletti V, Demedts M. Comparison of registries of interstitial lung diseases in three European countries. Eur Respir J Suppl. 2001;32:114s-118s.

11. Ohno S, Nakaya T, Bando M, Sugiyama Y. Idiopathic pulmonary fibrosis - results from a Japanese nationwide epidemiological survey using individual clinical records. Respirology. 2008;13(6):926-928.

12. Coultas DB, Zumwalt RE, Black WC, Sobonya RE. The epidemiology of interstitial lung diseases. Am J Respir Crit Care Med. 1994;150(4): 967-972.

13. Raghu G, Weycker D, Edelsberg J, Bradford WZ, Oster G. Incidence and prevalence of idiopathic pulmonary fibrosis. Am J Respir Crit Care Med. 2006;174(7):810-816.

14. Fernández Pérez ER, Daniels CE, Schroeder DR, et al. Incidence, prevalence, and clinical course of idiopathic pulmonary fibrosis: a population-based study. Chest. 2010;137(1):129-137.

15. Gribbin J, Hubbard RB, Le Jeune I, Smith CJ, West J, Tata LJ. Incidence and mortality of idiopathic pulmonary fibrosis and sarcoidosis in the UK. Thorax. 2006;61(11):980-985.

16. Navaratnam V, Fleming KM, West J, et al. The rising incidence of idiopathic pulmonary fibrosis in the UK. Thorax. 2011;66(6):462-467.

17. Kolek V. Epidemiology of cryptogenic fibrosing alveolitis in Moravia and Silesia. Acta Univ Palacki Olomuc Fac Med. 1994;137:49-50.

18. von Plessen C, Grinde O, Gulsvik A. Incidence and prevalence of cryptogenic fibrosing alveolitis in a Norwegian community. Respir Med. 2003;97(4):428-435.

19. Hodgson U, Laitinen T, Tukiainen P. Nationwide prevalence of sporadic and familial idiopathic pulmonary fibrosis: evidence of founder effect among multiplex families in Finland. Thorax. 2002;57(4):338-342.

20. Lai CC, Wang CY, Lu HM, et al. Idiopathic pulmonary fibrosis in Taiwan - a population-based study. Respir Med. 2012;106(11) $1566-1574$.

21. Hubbard R, Venn A, Lewis S, Britton J. Lung cancer and cryptogenic fibrosing alveolitis. A population-based cohort study. Am J Respir Crit Care Med. 2000;161(1):5-8.

22. Mannino DM, Etzel RA, Parrish RG. Pulmonary fibrosis deaths in the United States, 1979-1991. An analysis of multiple-cause mortality data Am J Respir Crit Care Med. 1996;153(5):1548-1552.

23. Olson AL, Swigris JJ, Lezotte DC, Norris JM, Wilson CG, Brown KK. Mortality from pulmonary fibrosis increased in the United States from 1992 to 2003. Am J Respir Crit Care Med. 2007;176(3):277-284.

24. Taskar VS, Coultas DB. Is idiopathic pulmonary fibrosis an environmental disease? Proc Am Thorac Soc. 2006;3(4):293-298.

25. Johnston ID, Prescott RJ, Chalmers JC, Rudd RM. British Thoracic Society study of cryptogenic fibrosing alveolitis: current presentation and initial management. Fibrosing Alveolitis Subcommittee of the Research Committee of the British Thoracic Society. Thorax. 1997;52(1):38-44.

26. Johnston I, Britton J, Kinnear W, Logan R. Rising mortality from cryptogenic fibrosing alveolitis. BMJ. 1990;301(6759):1017-1021.

27. Arakawa $\mathrm{H}$, Johkoh T, Honma K, et al. Chronic interstitial pneumonia in silicosis and mix-dust pneumoconiosis: its prevalence and comparison of CT findings with idiopathic pulmonary fibrosis. Chest. 2007;131(6): 1870-1876.

28. Copley SJ, Wells AU, Sivakumaran P, et al. Asbestosis and idiopathic pulmonary fibrosis: comparison of thin-section CT features. Radiology. 2003;229(3):731-736.

29. Kitamura H, Ichinose $S$, Hosoya $T$, et al. Inhalation of inorganic particles as a risk factor for idiopathic pulmonary fibrosis - elemental microanalysis of pulmonary lymph nodes obtained at autopsy cases. Pathol Res Pract. 2007;203(8):575-585.
30. Scott J, Johnston I, Britton J. What causes cryptogenic fibrosing alveolitis? A case-control study of environmental exposure to dust. BMJ. 1990;301:1015-1017.

31. Iwai K, Mori T, Yamada N, Yamaguchi M, Hosoda Y. Idiopathic pulmonary fibrosis. Epidemiologic approaches to occupational exposure. Am J Respir Crit Care Med. 1994;150(3):670-675.

32. Hubbard R, Lewis S, Richards K, Johnston I, Britton J. Occupational exposure to metal or wood dust and aetiology of cryptogenic fibrosing alveolitis. Lancet. 1996;347(8997):284-289.

33. Mullen J, Hodgson M, DeGraff A, Godar T. Case-control study of idiopathic pulmonary fibrosis and environmental exposures. J Occup Environ Med. 1998;40(4):363-367.

34. Baumgartner KB, Samet JM, Coultas DB, et al. Occupational and environmental risk factors for idiopathic pulmonary fibrosis: a multicenter case-control study. Collaborating Centers. Am J Epidemiol. 2000;152(4):307-315.

35. Miyake Y, Sasaki S, Yokoyama T, et al. Occupational and environmental factors and idiopathic pulmonary fibrosis in Japan. Ann Occup Hyg. 2005;49(3):259-265.

36. Baumgartner KB, Samet JM, Stidley CA, Colby TV, Waldron JA. Cigarette smoking: a risk factor for idiopathic pulmonary fibrosis. Am J Respir Crit Care Med. 1997;155(1):242-248.

37. Steele MP, Speer MC, Loyd JE, et al. Clinical and pathologic features of familial interstitial pneumonia. Am J Respir Crit Care Med. 2005;172(9):1146-1152.

38. Hubbard R, Cooper M, Antoniak M, et al. Risk of cryptogenic fibrosing alveolitis in metal workers. Lancet. 2000;355(9202):466-467.

39. Gustafson T, Dahlman-Höglund A, Nilsson K, Ström K, Tornling G, Torén K. Occupational exposure and severe pulmonary fibrosis. Respir Med. 2007;101(10):2207-2212.

40. Pinheiro GA, Antao VC, Wood JM, Wassell JT. Occupational risks for idiopathic pulmonary fibrosis mortality in the United States. Int $J$ Occup Environ Health. 2008;14(2):117-123.

41. García-Sancho C, Buendía-Roldán I, Fernández-Plata MR, et al. Familial pulmonary fibrosis is the strongest risk factor for idiopathic pulmonary fibrosis. Respir Med. 2011;105(12):1902-1907.

42. Awadalla NJ, Hegazy A, Elmetwally RA, Wahby I. Occupational and environmental risk factors for idiopathic pulmonary fibrosis in Egypt: a multicenter case-control study. Int J Occup Environ Med. 2012;3(3): $107-116$.

43. Lee JS, Collard HR, Raghu G, et al. Does chronic microaspiration cause idiopathic pulmonary fibrosis? Am J Med. 2010;123(4):304-311.

44. Tobin RW, Pope CE, Pellegrini CA, Emond MJ, Sillery J, Raghu G. Increased prevalence of gastroesophageal reflux in patients with idiopathic pulmonary fibrosis. Am J Respir Crit Care Med. 1998;158(6): 1804-1808.

45. Raghu G, Freudenberger TD, Yang S, et al. High prevalence of abnormal acid gastro-oesophageal reflux in idiopathic pulmonary fibrosis. Eur Respir J. 2006;27(1):136-142.

46. Patti MG, Tedesco P, Golden J, et al. Idiopathic pulmonary fibrosis: how often is it really idiopathic? J Gastrointest Surg. 2005;9(8):1053-1058; discussion 1056-1058.

47. Gribbin J, Hubbard R, Smith C. Role of diabetes mellitus and gastrooesophageal reflux in the aetiology of idiopathic pulmonary fibrosis. Respir Med. 2009;103(6):927-931.

48. Lee JS, Ryu JH, Elicker BM, et al. Gastroesophageal reflux therapy is associated with longer survival in patients with idiopathic pulmonary fibrosis. Am J Respir Crit Care Med. 2011;184(12):1390-1394.

49. Lee JS, Collard HR, Anstrom KJ, et al. Anti-acid treatment and disease progression in idiopathic pulmonary fibrosis: an analysis of data from three randomized controlled trials. Lancet Respir Med. 2013;1(5): 369-376.

50. Devine MS, Garcia CK. Genetic interstitial lung disease. Clin Chest Med. 2012;33(1):95-110.

51. Lee HL, Ryu JH, Wittmer MH, et al. Familial idiopathic pulmonary fibrosis: clinical features and outcome. Chest. 2005;127(6): 2034-2041. 
52. Armanios MY, Chen JJ, Cogan JD, et al. Telomerase mutations in families with idiopathic pulmonary fibrosis. $N$ Engl J Med. 2007;356(13): 1317-1326.

53. Tsakiri KD, Cronkhite JT, Kuan PJ, et al. Adult-onset pulmonary fibrosis caused by mutations in telomerase. Proc Natl Acad Sci US A. 2007;104(18):7552-7557.

54. Nogee LM, Dunbar AE 3rd, Wert SE, Askin F, Hamvas A, Whitsett JA. A mutation in the surfactant protein $\mathrm{C}$ gene associated with familial interstitial lung disease. N Engl J Med. 2001;344(8):573-579.

55. Thomas AQ, Lane K, Phillips J, et al. Heterozygosity for a surfactant protein $\mathrm{C}$ gene mutation associated with usual interstitial pneumonitis and cellular nonspecific interstitial pneumonitis in one kindred. $\mathrm{Am} \mathrm{J}$ Respir Crit Care Med. 2002;165(9):1322-1328.

56. van Moorsel CH, van Oosterhout MF, Barlo NP, et al. Surfactant protein $\mathrm{C}$ mutations are the basis of a significant portion of adult familial pulmonary fibrosis in a dutch cohort. Am J Respir Crit Care Med. 2010;182(11):1419-1425.

57. Wang Y, Kuan PJ, Xing C, et al. Genetic defects in surfactant protein A2 are associated with pulmonary fibrosis and lung cancer. Am J Hum Genet. 2009;84(1):52-59.

58. Hodgson U, Pulkkinen V, Dixon M, et al. ELMOD2 is a candidate gene for familial idiopathic pulmonary fibrosis. Am J Hum Genet. 2006; 79(1):149-154.

59. Mushiroda T, Wattanapokayakit S, Takahashi A, et al; Pirfenidone Clinical Study Group. A genome-wide association study identifies an association of a common variant in TERT with susceptibility to idiopathic pulmonary fibrosis. J Med Genet. 2008;45(10):654-656.

60. Cronkhite JT, Xing C, Raghu G, et al. Telomere shortening in familial and sporadic pulmonary fibrosis. Am J Respir Crit Care Med. 2008; 178(7):729-737.

61. Diaz de Leon A, Cronkhite JT, Katzenstein AL, et al. Telomere lengths, pulmonary fibrosis and telomerase (TERT) mutations. PLoS One. 2010;5(5):e10680.

62. Seibold MA, Wise AL, Speer MC, et al. A common MUC5B promoter polymorphism and pulmonary fibrosis. $N$ Engl J Med. 2011;364(16): 1503-1512.

63. Zhang Y, Noth I, Garcia JG, Kaminski N. A variant in the promoter of MUC5B and idiopathic pulmonary fibrosis. $N \mathrm{Engl} \mathrm{J} \mathrm{Med}$. 2011;364(16):1576-1577.

64. Peljto AL, Zhang Y, Fingerlin TE, et al. Association between the MUC5B promoter polymorphism and survival in patients with idiopathic pulmonary fibrosis. JAMA. 2013;309(21):2232-2239.
65. Fingerlin TE, Murphy E, Zhang W, et al. Genome-wide association study identifies multiple susceptibility loci for pulmonary fibrosis. Nat Genet. 2013;45(6):613-620.

66. Noth I, Zhang Y, Ma SF, et al. Genetic variants associated with idiopathic pulmonary fibrosis susceptibility and mortality: a genomewide association study. Lancet Respir Med. 2013;1(4):309-317.

67. Almagro P, Calbo E, Ochoa de Echagüen A, et al. Mortality after hospitalization for COPD. Chest. 2002;121(5):1441-1448.

68. Martinez FJ, Safrin S, Weycker D, et al; IPF Study Group. The clinical course of patients with idiopathic pulmonary fibrosis. Ann Intern Med. 2005;142(12 Pt 1):963-967.

69. Song JW, Hong SB, Lim CM, Koh Y, Kim DS. Acute exacerbation of idiopathic pulmonary fibrosis: incidence, risk factors and outcome. Eur Respir J. 2011;37(2):356-363.

70. du Bois RM, Weycker D, Albera C, et al. Ascertainment of individual risk of mortality for patients with idiopathic pulmonary fibrosis. Am J Respir Crit Care Med. 2011;184(4):459-466.

71. Collard HR, Moore BB, Flaherty KR, et al; Idiopathic Pulmonary Fibrosis Clinical Research Network Investigators. Acute exacerbations of idiopathic pulmonary fibrosis. Am J Respir Crit Care Med. 2007;176(7):636-643.

72. Navaratnam V, Fogarty AW, Glendening R, McKeever T, Hubbard RB. The increasing secondary care burden of idiopathic pulmonary fibrosis: hospital admission trends in England from 1998 to 2010. Chest. 2013;143(4):1078-1084.

73. Collard HR, Ward AJ, Lanes S, Cortney Hayflinger D, Rosenberg DM, Hunsche E. Burden of illness in idiopathic pulmonary fibrosis. J Med Econ. 2012;15(5):829-835.

74. Hubbard R, Johnston I, Coultas DB, Britton J. Mortality rates from cryptogenic fibrosing alveolitis in seven countries. Thorax. 1996;51(7): 711-716.

75. Swigris JJ, Olson AL, Huie TJ, et al. Ethnic and racial differences in the presence of idiopathic pulmonary fibrosis at death. Respir Med. 2012;106(4):588-593.

76. Howlader N, Noone AM, Krapcho M, et al. SEER Cancer Statistics Review, 1975-2010 [webpage on the Internet]. Bethesda, MD: National Cancer Institute; 2012 [updated June 14, 2013]. Available from: http:// seer.cancer.gov/csr/1975_2010/,2013. Accessed August 16, 2013.
Clinical Epidemiology

\section{Publish your work in this journal}

Clinical Epidemiology is an international, peer-reviewed, open access journal focusing on disease and drug epidemiology, identification of risk factors and screening procedures to develop optimal preventative initiatives and programs. Specific topics include: diagnosis, prognosis, treatment, screening, prevention, risk factor modification, systematic

\section{Dovepress}

reviews, risk \& safety of medical interventions, epidemiology \& biostatical methods, evaluation of guidelines, translational medicine, health policies \& economic evaluations. The manuscript management system is completely online and includes a very quick and fair peer-review system, which is all easy to use. 